\title{
Alain Chartier, Le Quadrilogue Invectif
}

\section{Paola Cifarelli}

\section{(2) OpenEdition}

\section{Journals}

\section{Édition électronique}

URL : http://journals.openedition.org/studifrancesi/3664

DOI : 10.4000/studifrancesi.3664

ISSN : 2427-5856

\section{Éditeur}

Rosenberg \& Sellier

\section{Édition imprimée}

Date de publication : 1 décembre 2012

Pagination : $545-546$

ISSN : 0039-2944

\section{Référence électronique}

Paola Cifarelli, « Alain Chartier, Le Quadrilogue Invectif», Studi Francesi [En ligne], 168 (LVI | III) | 2012,

mis en ligne le 30 novembre 2015, consulté le 05 mars 2021. URL : http://journals.openedition.org/ studifrancesi/3664; DOI : https://doi.org/10.4000/studifrancesi.3664

\section{Ce document a été généré automatiquement le 5 mars 2021.}

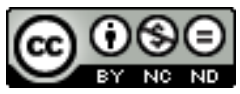

Studi Francesi è distribuita con Licenza Creative Commons Attribuzione - Non commerciale - Non opere derivate 4.0 Internazionale. 


\title{
Alain Chartier, Le Quadrilogue Invectif
}

\author{
Paola Cifarelli
}

\section{RÉFÉRENCE}

ALAIN CHARTIER, Le Quadrilogue Invectif édité par Florence BOUCHET, Paris, Champion, 2011

(«Classiques français du Moyen Age»168), pp. 148.

1 F. Bouchet propose ici une nouvelle édition du Quadrilogue Invectif, rédigé par Alain Chartier vers 1422, après celle qu'Eugénie Droz fit paraître en 1923 et révisa en 1950; né comme prolongement de la traduction en français moderne du même ouvrage, publiée en 2002, ce travail vise à fournir un texte plus correct, mieux ponctué et accompagné d'un glossaire plus complet par rapport à l'édition de 1923.

Le texte de base est constitué par le ms Paris, BnF, fr. 126, le même qu'avait adopté E. Droz; par contre, alors que cette dernière avait utilisé un seul ms. de contrôle (Paris, BnF, fr. 1124), le corpus éditorial est ici constitué de huit codex, choisis parmi les séries classées par J. Laidlaw sous les lettres A, H, J.

Un chapitre liminaire consacré au «statut éthique d'Alain Chartier» (p. VIII) insiste sur le rôle de maître de sagesse et d'orateur de celui-ci, qui utilise magistralement la rhétorique dans un but didactique en exploitant ce qu'on appellerait aujourd'hui la valeur pragmatique du langage. Après avoir illustré la tradition manuscrite, qu'on sait être particulièrement touffue pour cet ouvrage, l'A. signale les éditions anciennes pour passer ensuite à l'analyse linguistique. Celle-ci, claire et approfondie, permet entre autres de mettre en lumière quelques traits archaïsants particulièrement intéressants. Je me permettrai seulement quelques observations à propos de la phonétique, où l'alternance-age/-aige, décrite comme un phénomène marquant la fermeture de -a-, me paraît plutôt relever d'une oscillation graphique pour noter la palatalisation dans l'évolution du suffixe latin -aticu (p. XLII); pareillement, je ne vois pas de distinction entre l'alternance du type loables/louables et doleur/douleur, relevant toutes les deux du phénomène de l'ouisme (p. XLIII); encore, dans la section consacrée à la morphologie des substantifs, le choix d'exemples accompagnés d'adjectifs épicènes (Fortune puissant, quel 
aide) ne permet pas de juger à propos du genre des noms (p. xLIX); je me demande enfin si le douloureux infortune (p. $45,1.16$, commenté p. xuIx) ne serait pas plutôt à lire le douloureux infortuné.

Le texte est encore précédé des critères de transcription, qui paraissent judicieux compte tenu des caractéristiques du corpus éditorial, ainsi que d'une bibliographie complète et particulièrement utile, car elle permet de situer l'auteur et son texte dans le contexte littéraire, historique et idéologique de son époque.

5 Quant à l'édition, elle est soignée et le double étage de notes permet de bien saisir la mouvance du texte dans la tradition manuscrite. Les corrections du manuscrit de base, assez nombreuses, sont pour la plupart justifiées et toutes attestées dans les témoins retenus pour la collation. Toutefois, on a parfois l'impression que le charme d'une lectio facilior ait amené l'éditrice à amender un texte qui ne contient pas vraiment de contresens; je me bornerai à citer le cas de la correction de souldees en souldoyers sur la base d'un seul témoin parmi les manuscrits de contrôle (p.29, 1. 17: assailli de mes defendeurs et guerroyé des souldees (= 'tributs à payer') dont le paiement est fait de mon propre chatel).

6 Les notes, situées à la fin du texte, permettent de reconstruire efficacement le contexte qui a donné naissance à ce débat à quatre voix considéré l'un des chefs-d'œuvre de la littérature politique en moyen français. Ces remarques, très riches tant en informations et commentaires qu'en renvois bibliographiques, sont suivies du glossaire et de l'index des noms propres.

7 Enfin, les annexes permettent de mettre en perspective ce témoin important de la littérature 'engagée' pendant la Guerre de Cent Ans; la transcription du Lai de la Paix (1424-1425) d'après le manuscrit Toulouse, BM, 826, est suivie de trois rubriques introductives: celle du ms Paris, BnF, fr. 24440, celle de l'incunable publié par Colard Mansion vers 1477 et celle de l'édition parue chez Galliot du Pré en 1526. 